\title{
Attributes to be considered for a site to participate in a pharmaceutical clinical trial in Mexico: A proposal of minimum criteria
}

\author{
José L. Arredondo, Hilario E. Ávila-Armengol, Guillermo Castro-Farfán, Francisco F. Cons-Molina, \\ Guillermo González-Galvez, José G. González-González, Francisco Gutiérrez-Delgado, \\ Eduardo Lazcano-Ponce, Leobardo Sauque-Reyna, José L. Viramontes-Madrid*, \\ and Miriam Serrano-Andrade
}

Consejo de Investigadores Clínicos de APEIC (Asociación de Profesionales Especialistas en la Investigación Clínica A.C.), Mexico City, Mexico

\begin{abstract}
Objective: The objective of the study was to offer a parameter to assess the different types of sites participating in a pharmaceutical clinical trial in Mexico. Materials and methods: A board of clinical investigators recognized by the industry in Mexico reviewed and discussed the most common requirements for a site to participate in a clinical trial within our country. The board defined a minimum standard by consensus. Results: A list of 68 criteria was set, divided into six sections: (1) general conditions, (2) research team, (3) infrastructure, (4) standard operating procedures, (5) committees, and (6) supervision. Special considerations were included where needed. Conclusions: This is the first tool published in Mexico designed to optimize the site selection process for clinical trials sponsored by the industry.
\end{abstract}

Key words: Clinical research. Attributes. Criteria. Standard. Center. Site.

\section{Introduction}

The development of a single clinical pharmaceutical study can cost up to 100 million dollars; between $30 \%$ and $50 \%$ of this investment is lost on inefficiencies in the process ${ }^{1,2}$. A high percentage of these failures are due to the fact that selected sites do not have the minimum necessary infrastructure for the correct completion of clinical studies ${ }^{3,4}$. It is worth noting that today, in the world, there are no accepted standards for the requirements; a clinical research center ought to meet to carry out a pharmaceutical clinical assay.

In everyday practice, the guidelines followed are those established by the International Conference of Harmonization in its Good Clinical Practices chapter ${ }^{5}$, requirements which, directly or indirectly, are defined by some regulatory agencies, interpreted and respected 6 . Sometimes, guidelines proposed by different associations or academic organizations are taken into consideration ${ }^{7-10}$ and/or simply the sites follow the criterion imposed by the same pharmaceutics or companies dedicated to Clinical Research Organizations (CROs). There are several areas of opportunity to improve the efficiency, productivity, and quality of the operations of the different components in the process of clinical research.

The objective of this paper is to highlight the minimum attributes that ought to be taken into consideration in a research site so that it can comply with its commitment to the implementation, carrying out, and operation of a pharmaceutical clinical essay. For the purposes of

\section{Correspondence:}

*José L. Viramontes-Madrid

E-mail: Joseluis.viramontes@ apeic.org
Date of reception: 28-08-2019

Date of acceptance: 15-10-2019 DOI: 10.24875/RMU.19000123
Available online: 09-12-2019
Medicina Universitaria. 2019;21(4):180-184
www.medicinauniversitaria.org www.medicinauniversitaria.org under the CC BY-NC-ND license 
this report, the term "center" will be understood as a synonym of "site," and both concepts are encompassed in the Mexican regulatory definition of "Establishment of Medical Care ${ }^{11} . "$

\section{Materials and methods}

A board of nine clinical investigators with ample experience and good performance in trials within the pharmaceutical industry in Mexico (the list of participants can be found at the end of this text) was assembled. Each member of the board received the result of a search of medical literature on the quality of research sites ${ }^{6-10}$, and a list of criteria for the selection and evaluation of research centers used by the industry and CROs in Mexico. The board discussed each attribute and selected those that they considered by consensus as a minimum standard so that a center could conduct a pharmaceutical study.

\section{Results}

In table 1, there is a complete list of 68 attributes that conform to the proposed model, classified according to their principles: (1) criteria sustained in General Health Law, in a norm or a guideline, (2) recommendations made by the local authorities, without evident regulatory basis, (3) international guidelines, (4) additional recommendations made by the sponsor (industry or CROs), and (5) suggestions by the board by consensus. All criteria were divided into the following six sections for better management:

I. General aspects of the site: Attributes which reflect in general the experience and function of the site

II. Research team: Composition and qualifications of the personnel the center should have

III. Infrastructure: Requirements of space and necessary equipment for the proper performance of the center

IV. Standard operating procedures: Procedures that a research site must have as a minimum requested by the Commission of Sanitary Operation (COS by its Spanish acronym) of the Federal Commission for the Protection against Sanitary Risk (COFEPRIS by its Spanish acronym), to the establishments that have authorization to conduct a clinical trial ${ }^{12}$

V. Committees: Due to local Mexican regulation, each site must have three properly registered committees: an Ethics in Research Committee (ERC) registered with the National Bioethics Commission (CONBIOETICA by its Spanish acronym), a Research Committee, registered with the COFEPRIS, and a Biosafety Committee, also registered with COFEPRIS
VI. Supervision during the execution of the trial: Documentation of periodical personnel meeting through minutes.

\section{Discussion and conclusions}

Even though there are international proposals for the conformation of a research site ${ }^{13,14}$, the environment in which we operate in Mexico, and our own regulations demand the creation of a local model that responds to our specific needs.

This is the $1^{\text {st }}$ time that a standard in Mexico has been defined by agreement between independent experts, which allows the decision-makers of the different companies that sponsor research programs in our country to have a more objective and consensual approach in their center selection process for the assignment of a clinical study. This proposal may also help researchers who participate or who want to begin participating in these types of studies to search for a guideline with a national standard that can be accepted and acknowledged by all involved parties in our field.

To establish the list of criteria, the board had to discuss aspects of objective measurement or attributes related to the proper implementation and carrying out of a clinical pharmaceutical study. In each of these discussed criteria, there were different perspectives and the board set about searching for a consensus. Different aspects which may be considered controversial were approached, such as minimum necessary experience to be in charge of a study, preparation, and qualifications that the center's personnel must have, the minimum number of professionals which ought to make up the research group, and the amount of time each one should dedicate to their responsibilities in a trial. Concerning infrastructure, the board only recommended complying (as a minimum) with the space and equipment need related to the type of trial assigned, as well as the general and specific requirements established by the regulatory authority in our country.

Given the vast variability of perspectives and requirements within the industry and the methodological limitations of the work, we must be careful in the application of conclusions in this report. The minimum criteria model proposed is a guide, which can be of great help in the selection of a research center. However, by no means does this replace the attention that should be given to the following up of the site once the trial begins. Its final value should be evaluated in practice, searching to widen its reach and applicability. 
Table 1. Attributes for the participation of a research site or center in a clinical pharmaceutical study in Mexico

\begin{tabular}{|c|c|}
\hline I. General aspects & Considerations \\
\hline Site: Number of studies conducted completed & $\begin{array}{l}\text { Three studies completed. If the center } \\
\text { has }<3 \text { studies completed, they must } \\
\text { have a PI with } \geq 2 \text { studies completed in } \\
\text { the past } 3 \text { years }\end{array}$ \\
\hline Site: Number of active studies & $\begin{array}{l}\text { At least one. If the center does not have } \\
\text { active studies, it must have an IP with } \geq 2 \\
\text { studies completed in the past } 3 \text { years }\end{array}$ \\
\hline Site: Number of principal investigators & At least one \\
\hline Site: Number of subresearchers & $\begin{array}{l}\text { At least one. The same person can be a } \\
\text { subinvestigator and coordinator }\end{array}$ \\
\hline Site: Number of coordinators & $\begin{array}{l}\text { At least one. The same person can be a } \\
\text { subinvestigator and coordinator }\end{array}$ \\
\hline $\begin{array}{l}\text { Site: Number of Personnel for handling and sending } \\
\text { samples (certificate in IATA) }\end{array}$ & At least one. It can be any team member \\
\hline II. Research team & Considerations \\
\hline
\end{tabular}

Basis

Suggested by the council

Suggested by the council

Suggested by the council

Suggested by the council

Suggested by the council

Sponsor/CRO recommendation

\section{Basis}

Specialty related to the therapeutic class of the clinical study

At least one. If the researcher

has $<2$ years of experience, he must

have been a subinvestigator in at least two studies completed in the past

3 years

$6 \mathrm{~h}$ per week per study

Intermediate level, at least. Technical

English, reading level, and basic

PI: English level

conversation

Yes

Local regulation

Suggested by the council

General practitioner

$12 \mathrm{~h}$ per week per study

Intermediate level, at least. Technical

English, reading level, and basic

conversation

Yes

Technician

$12 \mathrm{~h}$ per week per study

Basic

Yes

Considerations

Yes

Yes

Yes

Yes

Yes

Exclusive, independent, and restricted area for material and supplies protection

Exclusive, independent, and restricted area to protect research products

Exclusive, independent, and restricted area for documentation safekeeping, including clinical records Exclusive, independent, and restricted area of handling and sample preparation

Sample collection area

Monitoring/auditing area
As part of the center or by agreement

The dead file can be external

As part of the center or by agreement

Yes

Puede ser un espacio compartido
International guidelines

Suggested by the council

Suggested by the council

International guidelines

Local regulation

Suggested by the council

Suggested by the council

Local regulation

Suggested by the counci Suggested by the council International guidelines

\section{Basis}

Local regulation

Local regulation

Local regulation

Local regulation

Sponsor/CRO recommendation

Sponsor/CRO recommendation

Sponsor/CRO recommendation

Sponsor/CRO recommendation

Local regulation

Sponsor/CRO recommendation 
Table 1. Attributes for the participation of a research site or center in a clinical pharmaceutical study in Mexico (Continued)

III. Infrastructure

Considerations

Basis

Medical emergency area

$24 \mathrm{~h}$ medical emergency area

Has an ambulance

Emergency cart

\begin{tabular}{l|l} 
Equipment maintenance and calibration program & Yes
\end{tabular}

Research product management

Investigation product management log Yes

Products identified (by protocol) $\quad$ Yes

Logbook of refrigerator and/or freezer temperature Yes

Temperature log of protected areas

Security

IBHW containers and proper handling Yes

\begin{tabular}{l|l} 
Fire extinguishers & Yes
\end{tabular}

Smoke detectors and alarms $\quad$ Yes

Safety signs $\quad$ Yes

Emergency contingency plan $\quad$ Yes

Pest control

\section{Standard operating procedures (SOPs)}

SOP: Issuance, review, approval, dissemination, and update of SOPs

SOP: Follow-up to the authorized protocols

SOP: Roles and responsibilities of the staff participating in the protocols

SOP: Selection of staff that is part of the group participating in the study

SOP: Recruitment of subjects that include the inclusion and exclusion criteria

SOP: Management, identification, temporary storage, collection, external transportation, and final disposal of infectious biological hazardous waste (IBHW)

SOP: Reports of adverse events according to the NOM-220-SSA1-2002

SOP: Management of conflicts of interest between the sponsor, research center, participating staff, and principal investigator

SOP: Transportation of biological samples that consider the type of container and records of transport conditions
As part of the center or by agreement As part of the center or by agreement

Yes

Yes

Internal or by agreement

When the study requires it, as part of the center or by agreement

When the study requires it, as part of the center or by agreement

Yes

Yes

Yes

Yes

Yes

Yes

Local regulation

National regulatory authority recommendation

National regulatory authority recommendation

Local regulation

Suggested by the council

International guidelines

International guidelines

Sponsor/CRO recommendation International guidelines International guidelines International guidelines International guidelines Local regulation

International guidelines International guidelines International guidelines International guidelines

Local regulation

Local regulation

Local regulation

Local regulation

Local regulation

Local regulation

\begin{tabular}{l|l} 
Considerations & Basis
\end{tabular}

Yes

National regulatory authority recommendation

National regulatory authority recommendation

National regulatory authority recommendation

National regulatory authority recommendation

National regulatory authority recommendation

National regulatory authority recommendation

National regulatory authority recommendation

National regulatory authority recommendation

National regulatory authority recommendation 
Table 1. Attributes for the participation of a research site or center in a clinical pharmaceutical study in Mexico (Continued)

\begin{tabular}{|l|l|l|}
\hline IV. Standard operating procedures (SOPs) & Considerations & Basis \\
\hline $\begin{array}{l}\text { SOP: Final destination of expired medicines } \\
\begin{array}{l}\text { SOP: Informed consent process, whether personalized/ } \\
\text { group and who is responsible for applying it }\end{array}\end{array}$ & Yes & $\begin{array}{l}\text { National regulatory authority } \\
\text { recommendation }\end{array}$ \\
\hline SOP: Confidentiality management & Yes & $\begin{array}{l}\text { National regulatory authority } \\
\text { recommendation }\end{array}$ \\
\hline V. Committees & Considerations & $\begin{array}{l}\text { National regulatory authority } \\
\text { recommendation }\end{array}$ \\
\hline $\begin{array}{l}\text { Research ethics committee registered with } \\
\text { CONBIOÉTICA }\end{array}$ & Internal or external & Basis \\
\hline Research committee registered with COFEPRIS & Internal or external & Local regulation \\
\hline Biosafety committee registered with COFEPRIS & Internal or external, according to protocol & Local regulation \\
\hline VI. Supervision during study execution & Considerations & Basis \\
\hline Minutes of research team meetings & As applicable & International guidelines \\
\hline
\end{tabular}

COFEPRIS: Federal Commission of Health Risk Protection; CONBIOETICA: National Bioethics Commission; IATA: International Air Transport Association; IBHW: infectious biological hazardous waste; PI: principal investigator; SI: subinvestigator; SOP: standard operating procedure.

\section{Acknowledgments}

This paper has been possible due to the Coordination and Logistic Support by the Association of Professional Specialist in Clinical Research (APEIC, acronym in Spanish, www.apeic.org).

\section{Conflicts of interest}

The authors declare that there are no conflicts of interest.

\section{Funding}

All the funds received were from resources of the APEIC.

\section{Ethical disclosures}

Protection of human and animal subjects. The authors declare that no experiments were performed on humans or animals for this study.

Confidentiality of data. The authors declare that they have followed the protocols of their work center on the publication of patient data.

Right to privacy and informed consent. The authors declare that no patient data appear in this article.

\section{References}

1. Clinical Trials Analysis. Mexico Health Review. Mexico: Clinical Trials Analysis; 2018. p. 284-5.

2. Goldfarb NM. Clinical research: a time to change. J Clin Res Best Pract. 2014:10:1-2. Available from: http://www.firstclinical.com.

3. Minisman G, Bhanushali M, Conwit R, Wolfe GI, Aban I, Kaminski HJ, et al. Implementing clinical trials on an international platform: challenges and perspectives. J Neurol Sci. 2012;313:1-6.

4. An Industry in Crisis. The Escalating Cost to Society of Our Inability to Sustain the Performance of Clinical Research Sites Today and Into the Future. SCRS Society for Clinical Research Sites; 2014. Available from: http://www.myscrs.org.

5. International Council for Harmonization of Technical Requirements for Pharmaceuticals for Human Use (ICH). Integrated Addendum to $\mathrm{ICH}$ E6(R1): Guideline for Good Clinical Practice E6(R2). Available from: https://www.ich.org/fileadmin/Public_Web_Site/ICH_Products/Guidelines/ Efficacy/E6/E6_R2_Step_4_2016_1109.pdf.

6. Lopez-Pacheco MC, Pimentel-Hernández C, Rivas-Mirelles E, Arredondo-García JL. Normatividad que rige la investigación clínica en seres humanos y requisitos que debe cumplir un centro de investigación para participar en un estudio clínico en México. Acta Pediatr Mex. 2016;37:175-82.

7. Johnston SC, Austin CP, Lewis-Hall F. Voluntary site accreditation improving the execution of multicenter clinical trials. N Engl J Med. 2017; 377:1414-5.

8. Koski G, Kennedy L, Tobin MF, Whalen M. Accreditation of clinical research sites moving forward. N Engl J Med. 2018;379:405-7.

9. Johnston SC, Lewis-Hall F, Bajpai A, Blumenfeld TH, Goldschmidt P, Koski G, et al. It's Time to Harmonize Clinical Trial Site Standards. Perspectives. Discussion Paper Expert Voices in Health and Health Care; 2017.

10. Bajpai A, Koski G, Tobin M. Aiming High. ACRES. ICT; 2015. p. 32-36. Available from: http://www.samedanltd.com.

11. DOF: $17 / 07 / 2018$, DECRETO por el que se Reforman, Adicionan y Derogan Diversas Disposiciones del Reglamento de la Ley General de Salud en Materia de Prestación de Servicios de Atención Médica. Available from: https://www.dof.gob.mx/nota_detalle.php?codigo=5531691\&fecha=17/07/2018.

12. COFEPRIS, Acta de Verificación Sanitaria para Establecimientos que Realizan Ensayos Clínicos. Available from: https://www.gob.mx/cms/ uploads/attachment/file/172739/COS-AC-17.pdf.

13. ACRES-QC S001 ACRES Quality Continuum Standard for the Quality Management of Clinical Research Sites; ACRES (Alliance for Clinical Research Excellence and Safety), SASI (Site Accreditation and Standards Initiative), Available from: http://www.acresglobal.net.

14. SCRS, Society for Clinical Research Sites. Avaliable from: http://www. myscrs.org. 